\title{
TECNOLOGIA DE COMUNICAÇÃO E INFORMAÇÃO: Ferramentas de Promoção da Educação em Direitos Humanos
}

\author{
Ednaldo Antonio da Silva
}

Universidade Federal de Pernambuco - UFPE. Av. Prof. Moraes Rego, 1235 - Cidade Universitária. Recife/PE, Brasil. CEP 50670-901. http://lattes.cnpq.br/0072103608849976. https://orcid.org/0000-0002-1340-4851.ednaldo.antonio@bol.com.br

O objetivo deste trabalho foi analisar em que medida as Tecnologias de Informação e Comunicação (TICs) podem ser usadas em promoção e efetivação da Educação em Direitos Humanos na contemporaneidade. Método: 0 desenho metodológico usado foi a pesquisa bibliográfica. Resultados: As TICs devem fortalecer as políticas públicas de Direitos Humanos (DHs); incentivar a organização mais rápida e a síntese de conhecimentos; acelerar a adoção de inovações na rede de cuidados; ampliar os meios de formação que promovem a vigilância e a gestão de cuidados. Conclusão: As TICs são ferramentas eficazes no ensino-aprendizagem, formação e capacitação dos profissionais no desenvolvimento de suas práticas educativas, garantem o desenvolvimento de atitudes proativas, geram maior custo-benefício e possibilitam uma ação prática no desenvolver da solução de problemas diante de situações novas. Palavras-chave: Educação; direitos humanos; tecnologias.

\section{COMMUNICATION AND INFORMATION TECHNOLOGY:}

TOOLS FOR THE PROMOTION OF EDUCATION IN HUMAN RIGHTS

\section{ABSTRACT}

The objective of this study was to analyze the extent to which Information and Communication Technologies (ICTs) can be used in the promotion and implementation of Human Rights Education in contemporary times. Method: The methodological design used was the bibliographical research. Results: ICTs strengthen public policies on Human Rights; encourages faster organization and synthesis of knowledge; accelerates the implementation of innovations in the care network; the means of training that promotes surveillance and management of care. Conclusion: ICTs are effective tools in teaching-learning, training and qualification of professionals in the development of their educational practices, guarantees the development of proactive attitudes, generates greater cost-benefit and allows a practical action in the development of problem solving new situations.

Keywords: Education; human rights; technologies.

Recebido em: 26/9/2017

Aceito em: 16/10/2017 


\section{INTRODUÇÃO}

Atualmente existe uma preocupação com as crescentes violações dos Direitos Humanos (DHs) em todos os setores da sociedade, entre eles a escola. Ainda mais preocupantes são as ocorrências protagonizadas em todos os espaços da escola, outrora um local distante desses fatos. O cenário tem levado os agentes educacionais a pedir apoio aos equipamentos que compõem o Sistema de Garantia dos Direitos que promove e previne as situações como bulliyng, violência, abusos, uso e o tráfico de drogas, etc. Esses são fatores extraescolares derivados: da comunidade, da família, dos espaços públicos e coletivos como praças, rua, campo, quadra de esporte, etc., cujos efeitos repercutem na escola por meio da socialização entre os protagonistas: alunos, vigilantes, docentes, gestores, cozinheiros, etc.

As violações dos DHs na escola são compreendidas como além da indisciplina e alcançam, em algumas situações, o grau de crimes, resultando em um desfecho judicial, com desdobramentos aquém da capacidade de qualificação e técnica dos profissionais da educação. Isso resulta na cristalização de sentimentos de impotência dos docentes e gestores escolares. Assim, as cobranças surgem diante da sua responsabilidade de vislumbrar soluções que vão além de sua formação.

A violação aos $\mathrm{DHs}$ é um dos maiores desafios a serem enfrentados por nossa sociedade. Apontamos a importância de formação específica que trabalhe essas temáticas, que possibilite a utilização de ferramentas necessárias para lidarmos com todas as problemáticas no sentido de promover interferências no projeto político-pedagógico e, para os casos mais desafiadores, intervir com uma abordagem mais efetiva. Consideramos como questão de partida e central para esse trabalho: Em que medida as Tecnologias de Informação e Comunicação (TICs) podem ser usadas em garantia (promoção da efetivação) dos Direitos Humanos no contexto escolar?

O poder de interferência das TICs na cultura social evidencia-se nas ações das pessoas na efetivação das políticas nacionais, estaduais e municipais promotoras do processo de igualdade diante das omissões políticas e ideológicas que estruturam o espaço social que excluem, discriminam, minimizam, bloqueiam ou dificultam a vivência do direito do sujeito à liberdade. A partir disso, propomos como procedimento metodológico a pesquisa bibliográfica de caráter exploratório.

A pesquisa bibliográfica é um estudo sistematizado, com base em material acessível por meio de livros, revistas, dissertações, teses, artigos impressos e/ou na rede eletrônica. O procedimento de coleta das referências foi: seleção, fichamento, leitura dos textos e articulação com o tema abordado (VERGARA, 2003).

\section{TECNOLOGIAS DE INFORMAÇÃO E COMUNICAÇÃO (TICS): ESTRATÉGIA NA EDUCAÇÃO EM DIREITOS HUMANOS}

As TICs tornaram-se nos últimos anos uma importante ferramenta de interação, aprendizado, comunicação e produção de conhecimentos. Podemos consultar bancos de dados, acessar as redes, sistemas, realizar troca de informações, transações bancárias, estabelecer e manter relações pessoais, profissionais e institucionais e ensinar e aprender (SOBRAL, 2010). Essas tecnologias são operadas nos mais diferentes tipos de aparelhos eletrônicos, como computador, rádio, celular, smartphone, televisão, tablet, lousa digital, etc. 
Os meios pelos quais as TICs podem ser operacionalizadas são quase infinitos, tais como o e-mail, SMS, redes sociais (Skype, WhatsApp, Facebook, Badoo, MySpace, etc.) entre outros. Essas tecnologias usadas com a finalidade específica de aprendizado podem ser importantes instrumentos de promoção dos Direitos Humanos, sendo importante estruturarmos bem o plano de aplicação. Dessa forma podemos ensinar e analisar criticamente as propagandas, as músicas, os jingles, as vinhetas, os núncios, os filmes, as novelas, as fotos, as revistas, os jornais e como eles veiculam informações, etc.

Os alunos podem avaliar as potencialidades e riscos que algumas postagens trazem. Entendemos que a TICs, quando bem utilizadas, constituem-se em fortes aliadas para a formação de cidadãos comprometidos, conforme asseguram os artigos $5^{\circ}$, inciso IV e 220 da Constituição Federal de 1988 na promoção da liberdade de expressão (BRASIL, 1988), o fortalecimento institucional, o pensamento coletivo e a "[...] Cibercidadania - cidadania em rede" (RAMINELLI; FELTRIN, 2012, p. 252).

As TICs são ferramentas importantes para o alcance do aprendizado das pessoas distantes geograficamente, por meio da Educação a Distância (EaD). Para isso, Plano Nacional de Educação (PNE) orienta o governo a investir na infraestrutura no sentido de ofertar acesso gratuito a uma educação de qualidade.

As TICs na escola surgem pelas mudanças ocorridas nos últimos 20 anos. Elas criaram um sistema de ciberdemocracia (SALES; FREIRE, 2012). Por meio das TICs, nos interessamos mais pelas questões políticas do país. O docente pode usá-las em debates em busca da construção do saber (RODEGHERI; SANTOS, 2012).

O ativismo e a cibercidadania no Brasil tiveram seu reconhecimento na realização do Fórum Social Mundial em 2001 em Porto Alegre/RS, quando as ONGs e entidades não governamentais por meio das TICs espalharam suas reivindicações nas redes sociais, criando espaço de debate virtual, resultado em um despertar para construção dos direitos dos cidadãos. 0 êxito deu-se pela ruptura de velhos paradigmas e na comunicação virtual mais vez, por meio da comunicação de baixo custo, "[...] a abrangência ilimitada; velocidade de transmissão? (MORAES, 2001, p. 4).

Cabe aos docentes usarem frequentemente as TICs no contexto educacional no sentido de apontar meios para buscar informações e orientações de formação de multiplicadores para toda a comunidade. Principalmente diante do contexto social complexo e amplamente fragilizado por problemas que afetam o cotidiano escolar, que constituem a desestruturação dos referenciais familiares resultantes das mais variáveis formas de violações aos DHs. As TICs são uma estratégia didática que também possibilitam uma sistematização e tornam-se potenciais de sensibilização, aprendizado e mudanças quando adotadas pelos docentes como ferramenta de ensino (HOLLIDAY, 2006).

\subsection{Educação em Direitos Humanos e as TICs: um processo possível}

No panorama atual impera a cultura paternalista e autoritária em que uma parte da população ainda acredita que os direitos são dádivas, dadas a alguns e a outros não. O nosso desafio é superamos essa limitação por meio da vivência da Educação em Direitos Humanos (EDH) de forma sistemática, permanente no cotidiano das pessoas, pela formação de sujeitos de direitos (CANDAU, 2005). 
A EDH é uma prática concreta que direciona o questionamento, a avaliação, e a interferência nas dinâmicas de poder que, historicamente, marginalizaram alguns grupos formados por negros, mulheres, gays, crianças, idosos, índios, formados por pessoas que carregam as marcas da escravidão, do domínio, do abuso, da violência e as diversas formas de desigualdades. A EDH promove o sentimento de pertença e posiciona para a mudança, desperta surgimento do protagonismo social.

O protagonismo potencializa a consciência de tomarmos decisão sobre a nossa vida pessoal e a dimensão coletiva. As práticas potencializam ainda a participação ativa na sociedade e a organização, formando uma rede de proteção real construída pelo diálogo e comunicação efetiva e assertiva.

Efetiva no sentido de constituir uma comunicação não violenta que minimiza os conflitos, contribui na ação conjunta de transformação da cultura em construção de novos valores e crenças, que podem reestruturar, criar novas políticas públicas articuladas à Constituição Federal de 1988. Esse processo de mudança pode resultar na construção de sociedades verdadeiramente democráticas e humanas (CANDAU, 2005). As TICs atuam como elementos didáticos, técnicos, operacionais para a construção de identidades plurais de etnia e cultura que se dão pelo resgate da memória histórica que rompa com a cultura do silêncio e a impunidade.

As TICs formam nas pessoas o protagonismo no processo de aprender ao ensinar e, ao mesmo tempo, ensinar a aprender, tecendo uma rede de relações de valorização do local, da cidadania, da identidade e das experiências de vida. Amplia o leque de conhecimentos das diferentes dimensões da realidade diante do fortalecimento dos grupos em situação de vulnerabilidade.

As TICs associam texto, imagens, cores, sons, movimentos, etc., administradas por um profissional com experiência em promoção dos $\mathrm{DHs}$, despertam e resgatam o interesse de partilha das histórias de vidas, colocando-as como instrumento de transformação social e apontam o caminho para compreensão das ideologias, dinâmicas de poder, presentes em todos os vieses da vida nos aspectos simbólico, real e imaginário. Levam as pessoas a assumirem o seu papel como agentes transformadores do contexto no qual atuam, como ainda a compreenderem as determinações de sua realidade como meio de transformar o seu mundo (CANDAU; SACAVINO, 2013).

É nesse processo de acreditar nas transformações que podemos efetivar uma partilha dos bens e fortalecer os vínculos, elementos formadores da teia construída nas ações diárias. A EDH articulada às TICs, como prática pedagógica e didática na escola, usadas em palestras, oficinas, em debates, em programas de rádios escolar, em blogs, na rede social da escola, efetiva-se como prática social por apontar novos direcionamentos e engajados às políticas públicas rumo à mediação de conflito.

As TICs como ferramenta e instrumento da EDH fortalecem a todos por meio do trabalho sistemático de construção da autoestima resultante do senso ético, da postura e do respeito às diferenças individuais. Esse modo de fazer insere em cada ator social a concepção prática de conhecer melhor a realidade que favorece as atividades humanizadoras das pessoas, um auxílio para a descoberta das potencialidades e do enriquecimento da diversidade, no sentido de efetivar os Direitos Humanos. 
As aulas, as rodas de conversas, os debates, as feiras, seminários, os debates que usam TICs como ferramenta de produção da Educação em Direitos Humanos, por meio de filmes, músicas, textos, frases, imagens, sons, reportagens, vinhetas, anúncios, etc., partem do princípio de que somos capazes de multiplicarmos boas experiências na construção do nosso próprio conhecimento. Essa crença nos faz enfrentar os desafios que surgem em nosso cotidiano, por aprendermos a identificar e analisar, em alguns casos mapearmos as áreas e traçarmos os perfis vulneráveis que temos como meta interferir e intervir diretamente mediante a da análise de nossa sua história (SANTOS, 1997).

As TICs favorecem o sentimento de proximidade e humildade, ajudam a construir uma relação proximal. Levam as pessoas a se "conhecer, conviver e mediar a pluralidade de 'estranhezas' que se manifestam no mundo" (DANELI; AQUINO, 2016, p. 32). A EDH nos leva a nos conhecermos, nos vermos como autores de nossas descobertas. Apropriar os argumentos, para levar adiante os bons exemplos, modelos e experimentos que comprovam resultados positivos do fortalecimento dos vínculos comunitários (CANDAU; SACAVINO, 2013).

As TICs têm a capacidade de promover as melhorias necessárias para o desenvolvimento de novas habilidades para atuarem efetivamente na resolução dos conflitos, e em combate que "o desprezo, a indiferença e a marginalização do Outro incita o ódio, a vingança, o assassinato, as guerras, a violência" (DANELI; AQUINO, 2016, p. 32), como resultados das desigualdades.

Esse sentimento nos proporciona convicção, sentimento de descoberta, de elaboração de novas ideias. Ao constatarmos que somos autores da nossa própria formação, descobrimos, consequentemente, o caminho de aprender a aprender, a nos apropriarmos das ferramentas necessárias para fazermos a EDH diariamente. As TICs devem estar vinculadas com a reflexão, escuta, diálogo, análise e avaliações de situações que transmitam novos paradigmas de transformação social (LIBÂNEO, 2002).

A EDH visa, ainda, a qualificar todas estas portas de acesso aos Direitos Humanos no sentido de todos serem iguais, acolhidos e, quando precisarem, os grupos terem seu reconhecimento como grupos, além de garantir aos invisíveis e vulneráveis o acesso adequado aos DHs. É importante construirmos novos paradigmas por meio das TICs, oficinas, encontros, rodas de diálogo, partilhas, histórias e ciclos de amizade por meio de técnicas projetivas, filmes, dinâmicas, jogos e brincadeiras.

As TICs possibilitam o desenvolvimento de novos comportamentos, mediação dos conflitos, aprimoramento de sentimentos, opiniões e pontos de vista sobre nossa prática. Assim, os agentes educacionais medeiam a formação, estimulam o surgimento de novas compreensões, despertam novos valores que são transmitidos nas atitudes e ações. As TICs nos levam a mergulhar em novas leituras, dinâmicas, músicas, cantigas, vídeos, imagens, trechos literários, relatos de vida e em experiências concretas do fazer em $\mathrm{DH}$.

As TICs nos agrupam, formando uma rede de interação, no sentido de criar um enorme guarda-chuva, ou seja, um sistema de proteção efetivo, unido para fortalecer os fatores de proteção e de resiliência. Libâneo (2002) leva-nos à reflexão sobre o nosso fazer, despertando a criação de novas alternativas mais eficazes diante dos obstáculos inter e extrainstitucionais de nível pessoal, familiar, social e institucional. 
O mediador/facilitador desafia a reflexão e o trabalho da igualdade. É inegável o caráter aglutinador que essa interferência provoca, entretanto ainda são poucos os profissionais com formação em Direitos Humanos (MEIRA; ANTUNES, 2003). Torna-se urgente formar os atuais e novos profissionais em DH acerca da construção do processo de mudança de postura para sairmos dos trabalhos descontextualizados para uma atuação construtivista, inserida na realidade na qual as pessoas em situação de vulnerabilidade e invisibilidade se encontram (DIMENSTEIN, 1998).

O alcance da igualdade requer socialização de saberes, em que aprendemos uns com os outros. Ainda existem pessoas que usam a sua capacidade e habilidades para dominar. É importante articularmos as experiências vividas no cotidiano às políticas públicas e uma maior atuação política de estruturação ética no sentido de possibilitar melhores condições para o desenvolvimento das atividades que precisem de ações protetivas. Outro desafio é a cultura individualista e centralizada. É importante que, para que o processo de EDH seja efetivo, as TICs fortaleçam o modelo democrático, participativo, que garante a autonomia dos sujeitos, ou seja, que leve alguns atores sociais a mudar sua prática disfuncional.

\subsection{As TICs em Contribuição à Educação em Direitos Humanos}

As TICs podem ser ensinadas de forma construtivista aos alunos para que eles desenvolvam várias formas de fazer, dinamizar e multiplicar os princícpios dos DH. É importante promover a reflexão sobre suas ações, brincandeiras, comportamentos, reflexões quando estiverem fazendo uma ação e no momento de sua reflexão na ação (SCHÖN, 2000).

Podemos usar várias ferramentas por meio de qualquer aparelho eletrônico, máquina fotográfica, celular. Pode-se orientar os alunos a produzirem vídeos sobre temas referentes aos Direitos Humanos, levantar uma discussão sobre as violações aos direitos no entorno da escola, como falta de rampas, barras nos banheiros para pessoas cadeirantes (SEABRA, 2010).

Os alunos podem realizar entrevistas com cadeirantes, pessoas com necessidades especiais que estão com seus direitos violados. Pode-se também convidar membros das comunidades que compõem a rede para discutir sobre como promover a EDH na escola e seu entorno. As TICs são importantes instrumentos de promoção à conscientização crítica, ética, política e cidadã. Podemos, ainda, realizar documentários sobre a história das mulheres, tratar as questões de gênero, refletir sobre as dinâmicas de poder, como também buscar na Internet material que promova a igualdade.

Segundo Santos e Souza (2011), em efetivação da garantia dos direitos à educação, no Instituto dos Cegos, localizado no município de Campina Grande/PB, mediante um planejamento didático da professora e dos alunos com deficiência visual (pessoas cegas e com baixa visão), estas foram incluídas na área de educação, como ainda passaram a acessar os serviços de saúde, assistência social, arte, cultura e esportes. Foram inseridos nas escolas um software Dosvox e um leitor de telas (Jaws), que serviram de referencial pelo sistema digital ser flexível e adaptável, especialmente modelado, no sentido que as 180 pessoas naveguem e explorem diferentes contextos, permitindo adequação e inserção de dados. As TICs permitem que uma pessoa com deficiência visual interaja com a máquina de forma muito conveniente. 
As meninas e os meninos no contexto escolar passaram a jogar juntos no sentido de mudar "o modelo patriarcal" promovendo uma ressignificação de conceitos, inclusive para a “equidade de gênero" (SANTOS; MOITA, 2011, p. 104).

Podemos usar imagens, fotos, vídeos, cartoon e desenhos que retratem o problema que os alunos estejam vivenciando no cotidiano escolar, no sentido de despertar a reflexão crítica, explorar a busca da compreensão das condições sociais, culturais e educativas dos contextos das dinâmicas de poder e dominação, avaliando o que está implícito e explícito nas imagens e no cotidiano. Quando inserimos as TICs nas aulas, os alunos mostram-se mais interessados em aprender, compreender, e os seus pensamentos, emoções, tendem a mudar comportamentos, como também são estimulados a desenvolver sociabilidade, interação e cooperação. Com as TICs, as aulas ficam "[...] Mais envolventes, [...] mais flexíveis, transparentes, participativas e, nem por isso, banais" (DEMO, 2008, p. 7).

Quanto mais dinâmicas forem as aulas, maiores serão as experiências de cooperação, valorização interpessoal, liberdade, reflexão para instituir uma cultura de paz. Esses são os fundamentos da Educação em Direitos Humanos, que:

Colocam a necessidade à adoção de novas formas de organização educacional, de novas metodologias de ensino-aprendizagem, de atuação institucional, buscando superar paradigmas homogeneizantes (BRASIL, 2013, p. 501).

Por meio dos jogos eletrônicos, ferramentas das TICs são utilizadas como brincadeiras, em que se inserem regras claras e justas nas partidas e nas competições. É importante destacar que as interações experimentadas por meio dessas modalidades de TICs são um importante instrumento didático, prático e operacional de aplicação da EDH, no sentido de inserirmos de forma lúdica temas como igualdade racial, religiosa, sexual, social e cultural. Além disso, tal estratégia promove melhor qualidade de vida e desenvolvimento cognitivo.

Esse é o objetivo básico da EDH, a formação de sujeitos para "[...] vida e para convivência no exercício cotidiano como forma de vida e de organização social, política, econômica e cultural" (BRASIL, 2013, p. 503). As competições nos jogos eletrônicos empregadas com justiça promovem a igualdade. Podemos inserir ainda como estratégia de EDH a música, a criação de uma rádio escolar no sentido levar o/a(s) aluno/a(s) a aprenderem se divertindo e a serem protagonistas de seu fazer, além de aprenderem a selecionar músicas, criar programas e montar a grade de programação, trabalhar em grupo, de forma dinâmica, cooperativa e participativa, mobilizando a comunidade escolar para o empoderamento dos Direitos Humanos. Além do rádio, podemos usar ainda a filmagem, o registro fotográfico, a criação de blogs e páginas nas redes sociais com as postagens desses materiais produzidos, e também da transmissão ao vivo das atividades realizadas na rádio.

O material produzido pode ser difundido em blog, jornais, panfletos, banners e materiais que estimulem a participação, o debate de temas referentes ao cotidiano escolar. Podemos criar uma roda de debate com professores de várias áreas, convidar os membros da Rede: Sistema de Garantia de Direitos (SGD), Assistência Social, Saúde e Educação, para contribuírem na programação da rádio, ou, ainda, vídeos, ou filmes, ou jornal, que podem ser difundidos na escola e a todos que tiverem acesso ao material. 
As TICs criam um espaço de interação rico em ações e diversão, transformador do cotidiano, com a premissa de modificar e instaurar o exercício da cidadania e ética que forma sujeitos capazes de encarar a vida de forma mais humana (ACIOLI, 2014). Com isso, ressignificamos o aprendizado e proporcionamos a atuação na sociedade como Agente de Desenvolvimento Local ( $A D L)$, respeitando e valorizando o outro. As aulas que utilizam as TICs como vídeos, filmes, músicas, desenhos, jogos, blogs, fotos como recurso de análise possibilitam condições de conscientização sobre nossos direitos e nossas responsabilidades como atores sociais habilitados para conhecer os valores referentes à vida digna, e nos reconhecer como sujeitos de direitos, refletindo sobre nosso contexto social (SILVA, 2009).

É possível também construir uma evolução material da educação em momentos de uso de recursos tecnológicos sem a reação à avaliação de seus efeitos e causas. Podemos desobstruir os impedimentos existentes promovendo como resultado o acesso "[...] À informação, igualdade, a liberdade, respeito à privacidade, explodindo uma reação em cadeia de força de práticas sociais" (GONÇAVES, 2011, p. 62). As TICs, quando direcionadas à visibilidade ao discurso de poder, trazem à tona os conflitos para serem questionados e enfrentados.

É importante consultarmos os bancos de dados bibliográficos, os sistemas, registros eletrônicos em EDH, os dados regionais de intercâmbios, as teleconferências que nos orientem sobre como aplicar as Tecnologias da Informação e Comunicação como recursos de empoderamento dos DH (SILVA; ALBUQUERQUE, 2014). É importante conhecer as noções subjacentes, tais como a privacidade e confidencialidade dos dados, erros conceituais em julgamento, falhas na informação e como antecipar e lidar com eles, o raciocínio, métodos e oportunidades para a polarização, os princípios de eficácia, interações entre seres humanos e tecnologia.

Não precisamos nos tornar programadores de computador para projetar sistemas. Basta saber usar as TICs como consumidores informados, conhecer as potencialidades e as fragilidades. O nosso desafio é incorporar os temas propostos pelo Plano Nacional de Educação em Direitos Humanos (PNEDH) por meio de estratégias didáticas e práticas em todo o processo de formação da Educação Básica e superior, no sentido de sustentar a mudança de paradigmas, treinando os atores sociais para consolidação de uma nova cultura emancipatória de acesso à igualdade (BRASIL, 2010; SILVA; RIBEIRO; LINS, 2012).

Ainda há obstáculos no desenho curricular do Ensino Superior que precisam ser revisados referentes às crescentes demandas do trabalho prático da EDH dos futuros profissionais de todos os cursos e profissões que esse país formará, bem como os desafios na identificação ou, ainda, o recrutamento de profissionais ativistas dispostos a ensinar, mediar, orientar, forma eficaz e em tais tópicos um caminho que sustenta um senso de relevância para os profissionais, população em geral que estão focadas em seus papéis futuros. Os DHs ainda não são amplamente ensinados, trabalhados e vividos na educação em todas as suas etapas. De modo que:

Os grupos menos favorecidos, notadamente a população negra e a indígena, continuam [...] excluídos do sistema de ensino formal em razão de uma série de fatores, entres esses, o currículo que não respeita a diversidade étnico-racial e cultural [...], presente nos diferentes espaços educacionais (ARAÚJO, 2014, p. 153). 
Desse modo, as TICs integradas ao currículo em todas as suas modalidades podem ser usadas para resolução dos conflitos emergentes. São poucos, porém, os docentes em condições de mediar os conflitos decorrentes das violações dos direitos e promover uma EDH. É importante que haja formação que possibilite aos agentes educacionais habilidades, técnica, prática e didática para inserir na educação os princípios da democracia e dos Direitos Humanos na educação em sua globalidade (BRASIL, 2010).

Essas experiências e formações não são criadas rapidamente, mas muitas instituições acadêmicas e escolas têm tido dificuldade em preencher as vagas para docentes devido à falta de formação em EDH. Sobre isso, Assis (2014, p. 173) denuncia que apensar das

evoluções científicas e tecnológicas ainda têm sérias dificuldades em reconhecer o valor da alteridade e o outro como sujeito de direito e dignidade. [...] Criamos sofisticados equipamentos de comunicação, mas não aperfeiçoamos nossa capacidade de diálogo; avançamos nas descobertas sobre genomas e sinapses cerebrais, mas nos tornamos a cada dia, mais insensíveis às diferenças que constituem a humanidade.

Apesar dos desafios, a transição atual da Educação Básica, Superior e Pós-Graduação que usam TICs como facilitadoras para a EDH é emocionante e transformadora (PIMENTEL; COSTA, 2012). A educação é um direito universal e as TICs no contexto escolar proporcionam "[...] Uma maneira totalmente nova de ensinar e aprender" (2012, p. 52) e, por atuar como um serviço de fortalecimento para a justiça social e o exercício do acesso aos direitos com qualidade equanimemente distribuída (BRASIL, 2010).

As TICs, quando usadas adequadamente promovem a superação dos problemas escolares como bullying, homofobia, racismo e violência, por despertar nos alunos a reflexão de seus comportamentos, ações, atitudes e apontar o caminho de acesso aos bens e serviços garantidos; articulam os atores sociais para lutar pela consolidação, legitimação dos direitos; fomentar a criação de novas leis que garantam o acesso à cidadania (SILVA; NASCIMENTO, 2009).

Para isso, é importante que as TICs estejam articuladas ao projeto ético-político voltado para a promoção da liberdade, da igualdade, da justiça social, do respeito às diferenças e da construção da paz (implicada): "[...] Na formação de um cidadão ativo e crítico capaz de se reconhecer como sujeito de direitos" na escola (MERCADO; SILVA NEVES, 2012, p. 210).

As TICs constituem um bem público de um patrimônio, determinado pelo contexto histórico, político, social, econômico e científico pelos quais são articulados, gerados e desenvolvidos em torno da sociedade brasileira, em cumprimento da Constituição Federal de 1988 e seus desdobramentos, efetivados no PNEDH. Este fomenta a integração e ampliação dos sistemas de informação na construção de mecanismos de avaliação e monitoramento de sua efetivação, como também a adoção de políticas para o desenvolvimento de tecnologias socialmente inclusivas, emancipatórias e ambientalmente sustentáveis (Brasil, 2010).

A EDH que adota as TICs no ambiente escolar fortalece os instrumentos de prevenção nas situações de vulnerabilidade e risco pessoal e social dos alunos e suas famílias, de modo que as pessoas reflitam sobre os impactos das situações de violações aos direitos e "tracem novas soluções que promovam o equilíbrio social, tornando os Direitos Humanos a práxis da nossa vida comum" (DANELI; AQUINO, 2016, p. 34), resultando com isso, conforme aponta Brasil (2010), na redução das desigualdades, causa geradora da violência. 


\section{CONSIDERAÇÕES FINAIS}

Neste trabalho de revisão bibliográfica propusemo-nos a analisar em que medida as Tecnologias de Informação e Comunicação (TICS) podem ser usadas na promoção e efetivação da Educação em Direitos Humanos na contemporaneidade. Evidenciamos o uso de diferentes conceitos, bem como as diversas visões sobre as tecnologias de informações que buscam concretizar as estratégias de promoção aos Direitos Humanos, como também das percepções sobre como trabalhar em uma educação mais efetiva.

Observamos a importância do desenvolvimento de competências específicas, em especial em Direitos Humanos para darmos conta da complexidade da demanda das situações que experimentamos no cotidiano escolar como o preconceito, homofobia, bullying, violência, que geram sofrimento pela presença do medo. Evidenciamos que a violação dos Direitos Humanos no ambiente escolar consiste em um grande desafio a todos os profissionais envolvidos com os alunos e apontamos para a necessidade da formulação e reformulação de novas práticas voltadas ao coletivo.

As TICs devem ser usadas para o fortalecimento dos vínculos dos laços afetivos que criam resolução dos problemas, fortalecimento da rede de proteção comunitária, as instituições sociais: família, organizações sociais para agregar em um trabalho em redes. Não podemos negar que as TICs contribuem significativamente para o desenvolvimento da humanidade. É importante não deixá-las influenciar totalmente no modo de ser do sujeito. Entendemos que elas não devem substituir o papel do contato experimentado por duas pessoas face a face, olho no olho. As TICs, portanto, não devem ser adotadas como a única fonte de progresso.

Ressaltamos que as TICs também enaltecem os valores do mercado, do consumo, e, muitas vezes, deixam de influir sobre aos valores éticos. Desse modo, não devemos substituir o contato humano pelo contato virtual. As políticas públicas ainda são incipientes para a promoção dos DHs. É importante que a criação de políticas públicas voltadas para uma conscientização e produção de TICs promova uma cultura de paz que reverbere o uso consciente das TICs.

É importante direcionarmos o nosso olhar para a questão das informações, comunicação vinculada nos espaços sociais no sentido que elas aproximem e não distanciem. A EDH deve ser efetivada de diferentes versões sobre os fatos da realidade, transmitida mediante textos narrativos, descritivos e histórias ficcionais e fantasias, de modo a causar reação fisiológica satisfatória em risos, lágrimas, suspense e aventura; som, barulho, música, dança, esporte e muitas e variadas imagens, com muitas cores e movimentos que resultem em novos pensamentos, comportamentos assertivos a curto, longo e médio prazos.

\section{REFERÊNCIAS}

ACIOLI, C. G. A educação na sociedade de informação e o dever fundamental estatal de inclusão digital. 2014. Tese (Doutorado) - Pontifícia Universidade Católica do Rio Grande do Sul - PUCRS, Programa de Pós-Graduação em Direito da Faculdade de Direito, Porto Alegre, 2014.

ARAÚJO, J. A. Educação e desigualdade: a conjuntura atual do ensino público no Brasil. Revista Direitos Humanos e Democracia, v. 2, n. 3, p. 125-157, 2014.

ASSIS, C. L. Educação em Direitos Humanos e o mal-estar em educar na pós-modernidade: uma discussão interdisciplinar a partir da psicanálise. Revista Direitos Humanos e Democracia, v. 2, n. 3, p. 158-176, 2014. 
BRASIL. Constituição da República Federativa de 1988. Brasília, DF: Subchefia para Assuntos Jurídicos; Casa Civil da Presidência da República, 1988.

BRASIL. Secretaria de Direitos Humanos da Presidência da República. Programa Nacional de Direitos Humanos (PNDH-3). Brasília: SEDH/PR, 2010.

BRASIL. Ministério da Educação; Secretaria de Educação Básica; Secretaria de Educação Continuada, Alfabetização, Diversidade e Inclusão; Conselho Nacional da Educação. Diretrizes Curriculares Nacionais Gerais da Educação Básica. Brasília: MEC; SEB; Dicei, 2013.

CANDAU, V. M. A configuração de uma educação em direitos humanos. Educação em direitos humanos: desafios atuais. In: Educação em Direitos Humanos: fundamentos teórico-metodológicos. Rio de Janeiro: [s.n.], 2005. p. 397-412. Cap. III.

CANDAU, V.; SACAVINO, Suzana. Educação em direitos humanos e formação de educadores. Educação, Porto Alegre, v. 36, n. 1, p. 59-66, 2013.

DANELI, J. C.; AQUINO, S. R. F. Qual educação para os direitos humanos? Revista Direitos Humanos e Democracia, v. 4, n. 8, p. 3-37, 2016.

DEMO, Pedro. TICS e educação. São Paulo: Cortez, 2008.

DIMENSTEIN, M. D. B. O psicólogo nas Unidades Básicas de Saúde: desafios para a formação e atuação profissionais. Revista Estudos de Psicologia, Natal, RN, v. 3, n. 1, 1998.

GONÇALVES, V. H. P. Inclusão digital como direito fundamental. 2011. Dissertação (Mestrado) - Universidade de São Paulo - USP, São Paulo, 2011.

HOLLIDAY, O. J. Para sistematizar experiências. 2. ed. Brasília: MMA 2006. (Revista -Série monitoramento e avaliação).

LIBÂNEO, J. C. Reflexividade e formação de professores: outra oscilação do pensamento pedagógico brasileiro? In: PIMENTA, S. G.; GHEDIN, E. (org.). Professor reflexivo no Brasil: gênese e crítica de um conceito. São Paulo: Cortez, 2002.

MEIRA, M. E.; ANTUNES, M. A. Psicologia escolar: práticas críticas. São Paulo: Casa do Psicólogo, 2003.

MERCADO, L. P. L.; SILVA NEVES, Y. P. C. A escola como espaço dos direitos humanos. In: RIBEIRO, Mara Rejane Alves Nunes; RIBEIRO, Getulio Couto (org.). Educação em direitos humanos: diálogos interdisciplinares. Maceió: Editora Universitária da Edufal, 2012. p. 199-220.

MORAES, D. O ativismo digital. Rio de Janeiro: Universidade Federal Fluminense, 2001. p. 1-14.

PIMENTEL, F. S. C.; COSTA, C. J. S. A. O tutor e as interações no ambiente virtual de aprendizagem. In: RIBEIRO, M. R. A. N.; RIBEIRO, G. C. (org.). Educação em direitos humanos: diálogos interdisciplinares. Maceió: Editora Universitária da Edufal, 2012. p. 51-66.

RAMINELLI, F. P.; FELTRIN, L. P. Blogs no Poder Judiciário brasileiro: entre a liberdade de expressão e a potencial violação do direito à honra. In: VERONESE, A.; ROVER, A. J.; AYUDA, F. G. (coord.). O novo constitucionalismo Latino Americano: desafios da sustentabilidade. ENCONTRO NACIONAL DO CONPEDI, 21., 2012. Niterói. Anais [...]. Niterói, RJ. Florianópolis: Funjab, 2012. p. 249-265.

RODEGHERI, L. B.; SANTOS, N. F. Desafios e (in)possibilidades de participação democrática na blogosfera. In: Sistemas Jurídicos e Direitos Fundamentais, Individuais e Coletivos. ENCONTRO NACIONAL DO CONPEDI, $21 ., 2012$. Florianópolis. Anais [...]. Florianópolis: Funjab, 2012. p. 4.625-4.650.

SALES, T. S.; FREIRE, G. Ma . C. A. Análise dos portais da transparência nos Estados brasileiros e a concretização da ciberdemocracia. In: Sistemas Jurídicos e Direitos Fundamentais, Individuais e Coletivos. ENCONTRO NACIONAL DO CONPEDI, 21., 2012. Florianópolis. Anais [...]. Florianópolis: Funjab, 2012. p. 4.449-4.474.

SANTOS, B. S. Uma concepção multicultural dos direitos humanos. São Paulo: Cedec - Revista de Cultura e Política, Lua Nova, n. 39, p. 105-124, 1997.

SANTOS, A. L. P.; MOITA, F. Mạ G. C. Os jogos como contextos curriculares: um estudo das construções de gênero no The SIMS. In: SOUSA, R. P.; MIOTA, F. M. C. S. C.; CARVALHO, A. B G. (org.). Tecnologias digitais na educação. Campina Grande: EDUEPB, 2011. p. 105-129.

SANTOS, L. P.; SOUZA, R. P. Novas tecnologias e pessoas com deficiências: a informática na construção da sociedade inclusiva? In: SOUSA, R. P.; MIOTA, F. M. C. S. C.; CARVALHO, A. B G. (org.). Tecnologias digitais na educação. Campina Grande: EDUEPB, 2011. p. 75-103.

SCHÖN, D. A. Educando o profissional reflexivo: um novo design para o ensino e a aprendizagem. Porto Alegre: Artmed, 2000.

SEABRA, C. Tecnologias na escola. Porto Alegre: Telos Empreendimentos Culturais, 2010. 
SILVA, E. A. Uma reflexão psicossocial da linguagem na formação da subjetividade humana. In: SIMPÓSIO AMBIENTALISTA BRASILEIRO NO CERRADO, 15., 2009. Goiânia: Enciclopédia Biosfera, S. Esp., v. 5, n. 8, p. 1-15, 2009. SILVA, E. A.; ALBUQUERQUE, R. N. A comunicação de massa e a cultura da virtualidade: uma fragmentação dos vínculos familiares e sociais. Síndromes - Revista Multidisciplinar do Desenvolvimento Humano, v. 4, p. 22-28, 2014.

SILVA, E. A.; NASCIMENTO, C. A. D. Um estudo psicossocial da mídia. In: Juventude e Família: encontros e desencontros na sociedade contemporânea. JONIC - JORNADA DE INICIAÇÃO CIENTÍ́FICA DA FIR, 8., 2009. Recife: COPPE; ESTÁCIO; FIR, 2009.

SILVA, J. F.; RIBEIRO, M. R.; LINS, M. A. T. A educação em direitos humanos no âmbito das políticas públicas: contribuições ao debate sobre o projeto ético-político do Serviço Social. In: RIBEIRO, M. R. A. N.; RIBEIRO, G. C. (org.). Educação em direitos humanos: diálogos interdisciplinares. Maceió: Edufal, 2012. p. 343-368.

SOBRAL, Ma N. Pedagogia online: discursos sobre práticas educativas em ambientes virtuais de aprendizagem. In: MACHADO, G. J. C. (org.). Educação e ciberespaço: estudos, propostas e desafios. Aracaju, SE: Virtus, 2010.

VERGARA, S. C. Projetos e Relatórios de Pesquisa em Administração. São Paulo: Atlas, 2003. 